Article

\title{
Enhancing the Mechanical and Electrical Properties of Poly(Vinyl Chloride)-Based Conductive Nanocomposites by Zinc Oxide Nanorods
}

\author{
Feng Qiu, Guangjian He *, Mingyang Hao and Guizhen Zhang \\ National Engineering Research Center of Novel Equipment for Polymer Processing, Key Laboratory of Polymer \\ Processing Engineering, Ministry of Education, School of Mechanical and Automotive Engineering, South China \\ University of Technology, Guangzhou 510640, China; qiufeng868@gmail.com (F.Q.); \\ hmyang1992@163.com (M.H.); guizhenzhang@scut.edu.cn (G.Z.) \\ * Correspondence: hegj@scut.edu.cn
}

Received: 4 September 2018; Accepted: 24 October 2018; Published: 30 October 2018

check for updates

\begin{abstract}
A simple approach to decorate multi-walled carbon nanotube (MWCNT)-reduced graphene oxide (RGO) hybrid nanoparticles with zinc oxide $(\mathrm{ZnO})$ nanorods is developed to improve the electrical and mechanical properties of poly(vinyl chloride) (PVC)/MWCNT-RGO composites. The ZnO nanorods act as "joint" in three-dimensional (3D) MWCNT-RGO networks and the hybrid particles strongly interact with PVC chains via p- $\pi$ stacking, hydrogen bonds, and electrostatic interactions, which we confirmed by scanning electron microscopy (SEM) and Raman analysis. By introducing the $\mathrm{ZnO}$ nanorods, the RGO-ZnO-MWCNT hybrid particles increased $160 \%$ in capacitance compared with MWCNT-RGO hybrids. Moreover, the addition of RGO-ZnO-MWCNT to PVC resulted in the mechanical properties of PVC being enhanced by $30.8 \%$ for tensile strength and $60.9 \%$ for Young's modulus at the loadings of 2.0 weight percent (wt.\%) and $1.0 \mathrm{wt.} \%$, respectively. Meanwhile, the electrical conductivity of PVC increased by 11 orders of magnitude, from $1 \times 10^{-15} \mathrm{~S} / \mathrm{m}$ to $1 \times 10^{-4} \mathrm{~S} / \mathrm{m}$ for MWCNT-ZnO-RGO loading at $5.0 \mathrm{wt} . \%$.
\end{abstract}

Keywords: poly(vinyl chloride); zinc oxide nanorods; multi-walled carbon nanotubes-reduced graphene oxide hybrid nanoparticles; nanocomposites

\section{Introduction}

Polymeric nanocomposites, composed of polymers and nanofillers dispersed in a polymer matrix, have attracted the attention of researchers worldwide for their widespread application in the fields of chemistry, machinery, and optics [1-3]. In the past few decades, poly(vinyl chloride) (PVC), as a host polymer matrix in polymeric nanocomposites, caught much of the attention of global researchers due to its excellent chemical stability, bio-compatibility and low cost [4-6]. Based on PVC as a matrix of high-performance nanocomposites, the present challenge depends on the preparation of a satisfactory reinforcing filler, which can uniformly disperse and have strong interfacial interaction with the PVC matrix. Therefore, the need to find such a suitable filler in order to prepare high-performance nanocomposites is apparent.

Multi-walled carbon nanotubes (MWCNTs) are a prominent nanofiller to enhance the properties of polymer composites as a result of its unique combination of properties such as excellent chemical stability and excellent electrical, thermal and mechanical properties [7-9]. However, MWCNTs, due to their strong chemical inertness, make it difficult to disperse well in the polymer matrix, and their interface with the polymer matrix is very weak. Therefore, to obtain a better performance of the polymer material, the nanotubes are usually modified by either covalent or non-covalent methods [10]. Covalent functionalization involves either the direct attachment of functional groups to the graphitic 
surface or by linking functional groups which are inherent defects on the carbon nanotube's (CNT's) surface [10]. The functional groups, such as carboxyl and hydroxyl, can be introduced by chemical treatment, which can be used to either "graft from" or "graft to" polymers from the surface of CNTs [11]. Shadpour Mallakpour's group improved the compatibility between PVC and MWCNTs through chemical treatment of carboxylated multi-walled carbon nanotubes (MWCNTs-COOH) with thiamine (Tm). This process achieved better CNT dispersion and enhanced mechanical properties of PVC-based nanocomposites [12-15]. Moreover, the combination of CNTs and graphene to improve the composite's performance is an effective method. Zou [16] used carbon nanotubes/graphene composites to improve capacitive deionization performance. Graphene was employed to disperse carbon nanotubes in silicone rubber [17]. In combination, reduced graphene oxides with carbon nanotubes results in synergies with polypropylene nanocomposites [18]. However, the covalent chemical modification approach would destroy the $\mathrm{sp}^{2}$ hybridization of the CNTs, and thus affect their intrinsic electrical, thermal and mechanical properties so that they could not fully exert their ability to reinforce the polymer composite materials.

Without damaging the surface structure of the MWCNTs through covalent functionalization, the non-covalent bond approach is an effective method of well-dispersing MWCNTs in the polymer matrix [19]. $\mathrm{CH}-\pi$ is capable of forming stable CNT-polymer dispersions in many solvents due to the fact that the interaction sites between the carbon nanotubes and the macromolecules are large numbers [20]. Furthermore, aromatic compounds adsorbed to the surface of CNTs which employ $\pi-\pi$ stacking were also used to improve compatibility between MWCNTs and polymers [21-25].

It is well known that single transition metal oxide nanoparticles, dissimilar from atomic and bulk counterparts, such as copper oxide ( $\mathrm{CuO})$ [26,27], zinc oxide $(\mathrm{ZnO})$ [28], ferroferric oxide $\left(\mathrm{Fe}_{3} \mathrm{O}_{4}\right)$ [29,30] and tantalum oxide $\left(\mathrm{Co}_{3} \mathrm{O}_{4}\right)$ [31] exhibit special physical and chemical properties due to their large specific surface area and quantum size effects. In previous works, some researchers have demonstrated that adding metal oxides like $\mathrm{ZnO}$ particles to a PVC matrix can enhance the mechanical properties because of the strong interfacial interactions formed with PVC molecular chains. [32,33]. If these nanoparticles are present among MWCNTs, the strong attractive interactions between adjacent CNTs can be weakened, along with the overall specific surface area. Thus, $\mathrm{ZnO}$ might be able to help with the dispersion of MWCNTs and prevent their re-agglomeration in polymer [34].

In our work, we prepared MWCNT-ZnO-reduced graphene oxide (RGO) hybrid particle fillers, then used them to modify PVC for better mechanical and electrical performance. The precursor graphene oxide (GO) of RGO was used to disperse MWCNTs well in solution. Single ZnO nanorods interact strongly with MWCNTs and RGO through $\mathrm{p}-\pi$ stacking/electrostatic interaction. They uniformly disperse in three-dimensional (3D) networks, which consist of one-dimensional (1D) MWCNTs and two-dimensional (2D) RGOs similar to the "joints" in fishing nets, increasing the mechanical properties of the nanocomposites. Hydrogen bonds or electrostatic attraction interactions also exist between the $\mathrm{ZnO}$ and the PVC molecular chains. So, we prepared the MWCNT-ZnO-RGO hybrid particles that can be well-dispersed in the PVC matrix. With their strong interfacial interactions with the minimal addition of hybrid particles, the mechanical properties and electrical conductivity of the nanocomposite materials were substantially improved.

\section{Experimental}

\subsection{Materials}

The PVC was purchased from Sichuan Jinlu Resin Co. Ltd. (Deyang, China). The zinc nitrate hexahydrate $\left(\mathrm{Zn}\left(\mathrm{NO}_{3}\right)_{2} \cdot 6 \mathrm{H}_{2} \mathrm{O}, 99.0 \%\right)$, sodium hydroxide $(\mathrm{NaOH}, 96.0 \%)$ and hydrazine hydrate (80.0\% aq.) were obtained from Chengdu Kelong Chemical Reagent Factory (Chengdu, China) and Chongqing Chuandong Chemical Co. Ltd. (Chongqing, China), respectively. Graphene (layers $<40$, size: 6-10 $\mu \mathrm{m}$, thickness: 5-20 nm). The Tianjin Regent Chemical Co. Ltd. (Tianjin, China) offered $\mathrm{ZnO}$. The multi-walled nanotubes (MWCNTs, TNIM4, average diameter: $10-30 \mathrm{~nm}$, average length: 
10-30 $\mu \mathrm{m}$, purity: >95\%) were bought from Chengdu Organic Chemical Co. Ltd. (Chengdu, China), Chinese Academy of Sciences.

We have designed the following schematic diagram (Figure 1) to describe the role of $\mathrm{ZnO}$ in the two composites: (a) the conductivity is poor when no zinc oxide nanorods are added into the PVC/RGO-MWCNT composites. When the composites are subjected to a stretching force, the hybrid particles are easily pulled apart in the matrix and exhibit poor mechanical properties. (b) When zinc oxide nanorods are added into the PVC/RGO-MWCNT composites, it can be seen that the ZnO nanorods act as joints to connect the RGO-MWCNT fillers and PVC chains; thus, the interaction between the hybrid particles and the matrix is improved. Consequently, under the action of a stretching force, the PVC/RGO-ZnO-MWCNT composites have better electrical conductivity and mechanical properties.

(a) PVC/MWCNT-RGO
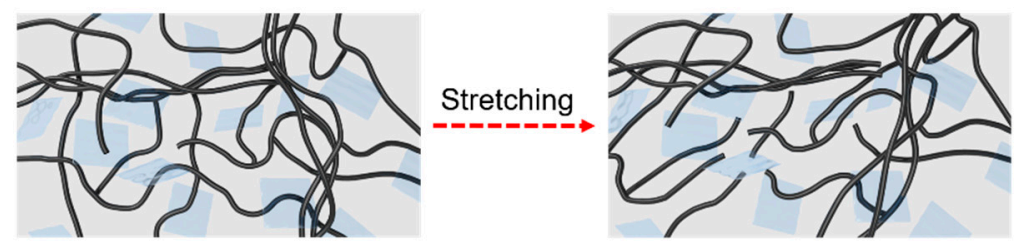

Electrical conductivity

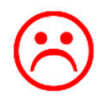

(b) PVC/MWCNT-ZnO-RGO

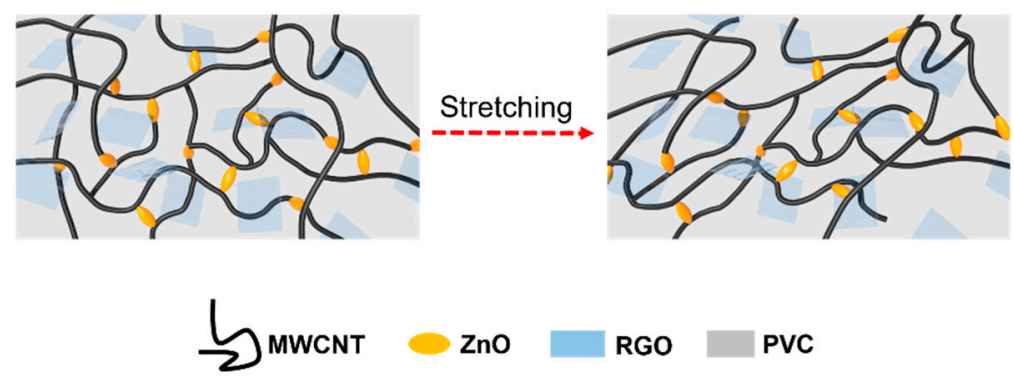

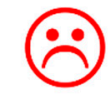

Mechanical property
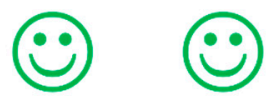

Figure 1. Scheme of multi-walled carbon nanotube (MWCNT)-reduced graphene oxide (RGO) particles (a) and MWCNT-zinc oxide ( $\mathrm{ZnO})-\mathrm{RGO}$ particles (b) in a poly(vinyl chloride) (PVC) matrix before and after stretching.

\subsection{Synthesis of MWCNT-ZnO-RGO Hybrid Particles}

The GO was prepared by the Hummers method [35]. Synthesis of MWCNT-ZnO-RGO hybrid particles: $225 \mathrm{~mL}$ of $1.0 \mathrm{mg} / \mathrm{mL}$ MWCNT aqueous solution and $75 \mathrm{~mL}$ of $1.0 \mathrm{mg} / \mathrm{mL}$ GO aqueous solution were added to a flask, then $0.073 \mathrm{~g}$ of $0.3 \mathrm{~mol} / \mathrm{L} \mathrm{Zn}\left(\mathrm{NO}_{3}\right)_{2}$ aqueous was added to the mixed solution. A diluted aqueous solution of sodium hydroxide was used to adjust the mixed solution to $\mathrm{pH}=10-11$ to form $\mathrm{Zn}(\mathrm{OH})_{4}{ }^{2-}$ particles [36]. Three milliliters of $80 \%$ hydrazine hydrate was added to the flask and then stirred at $100{ }^{\circ} \mathrm{C}$ for $24 \mathrm{~h}$ to form a yellow solution. After cooling, the solution was centrifuged to get the precipitate, which was then washed with deionized water and ethanol several times until the $\mathrm{pH}$ reached 7. The MWCNT-ZnO-RGO particles were obtained and dried. The synthetic procedure to obtain MWCNT-RGO hybrid particles was the same as MWCNT-ZnO-RGO, without the addition of the $\mathrm{Zn}\left(\mathrm{NO}_{3}\right)_{2}$ aqueous solution and sodium hydroxide.

\subsection{Preparation of $P V C / M W C N T-Z n O-R G O$ Nanocomposites}

The PVC/MWCNT-ZnO-RGO nanocomposite films were prepared by the solution blending method. MWCNTs-ZnO-RGO hybrid particles $(0.001 \mathrm{~g})$ were dispersed in $50 \mathrm{~mL}$ tetrahydrofuran (THF) and sonicated for $1 \mathrm{~h}$ for later use. PVC powder $(0.999 \mathrm{~g})$ was added to THF, which was reheated and stirred until a transparent solution was obtained. Then, these two solutions were blended and ultrasonicated for half an hour. Lastly, the blended solution was poured onto the glass plates to 
evaporate the THF at $50{ }^{\circ} \mathrm{C}$ in an oven, which formed a film with an approximate thickness of $50 \mu \mathrm{m}$. PVC with 0.1 weight percent (wt.\%), 0.2 wt. \%, 0.5 wt. $\%, 1.0$ wt. \%, 2.0 wt. $\%, 3.0$ wt. $\%$ and 5.0 wt. $\%$ MWCNT-ZnO-RGO filler content were employed to investigate the loading effect. As a control, the PVC/MWCNT-RGO composites were prepared with the same filler loadings. Table 1 shows all investigated nanocomposites.

Table 1. Summary of all investigated nanocomposite configurations.

\begin{tabular}{|c|c|c|}
\hline Samples & $\begin{array}{c}\text { Percentage of Filler Loading in } \\
\text { PVC (wt.\%) }\end{array}$ & Abbreviation \\
\hline PVC & 0 & PVC \\
\hline MWCNT-RGO & 0 & $\mathrm{C}-\mathrm{R}$ \\
\hline MWCNT-ZnO-RGO & 0 & $\mathrm{C}-\mathrm{Z}-\mathrm{R}$ \\
\hline PVC/0.1 wt.\% MWCNT-RGO & MWCNT-RGO = 0.1 wt. $\%$ & PVC/0.1 wt.\% C-R \\
\hline PVC/0.2 wt.\% MWCNT-RGO & MWCNT-RGO $=0.2 \mathrm{wt} . \%$ & PVC $/ 0.2$ wt. $\%$ C-R \\
\hline PVC/0.5 wt.\% MWCNT-RGO & MWCNT-RGO = 0.5 wt. $\%$ & PVC/0.5 wt.\% C-R \\
\hline PVC/1.0 wt. $\%$ MWCNT-RGO & MWCNT-RGO = 1.0 wt. $\%$ & PVC $/ 1.0$ wt. $\%$ C-R \\
\hline PVC $/ 2.0$ wt. $\%$ MWCNT-RGO & MWCNT-RGO = 2.0 wt. $\%$ & PVC $/ 2.0$ wt. $\%$ C-R \\
\hline PVC/3.0 wt.\% MWCNT-RGO & MWCNT-RGO = 3.0 wt. $\%$ & PVC $/ 3.0$ wt. $\%$ C-R \\
\hline PVC/5.0 wt.\% MWCNT-RGO & MWCNT-RGO = 5.0 wt. $\%$ & PVC/5.0 wt.\% C-R \\
\hline PVC/0.1 wt.\% MWCNT-ZnO-RGO & MWCNT-ZnO-RGO = 0.1 wt. $\%$ & PVC/0.1 wt. \% C-Z-R \\
\hline PVC/0.2 wt.\% MWCNT-ZnO-RGO & MWCNT-ZnO-RGO = 0.2 wt. $\%$ & PVC $/ 0.2$ wt. $\%$ C-Z-R \\
\hline PVC/0.5 wt.\% MWCNT-ZnO-RGO & MWCNT-ZnO-RGO = 0.5 wt. $\%$ & PVC $/ 0.5$ wt. $\%$ C-Z-R \\
\hline PVC/1.0 wt.\% MWCNT-ZnO-RGO & MWCNT-ZnO-RGO = 1.0 wt. $\%$ & PVC/1.0 wt. \% C-Z-R \\
\hline PVC/2.0 wt.\% MWCNT-ZnO-RGO & MWCNT-ZnO-RGO = 2.0 wt. $\%$ & PVC/2.0 wt. \% C-Z-R \\
\hline PVC/3.0 wt.\% MWCNT-ZnO-RGO & MWCNT-ZnO-RGO $=3.0$ wt. $\%$ & PVC/3.0 wt. \% C-Z-R \\
\hline PVC/5.0 wt.\% MWCNT-ZnO-RGO & MWCNT-ZnO-RGO = 5.0 wt. $\%$ & PVC/5.0 wt. \% C-Z-R \\
\hline
\end{tabular}

The weight ratio of MWCNT:RGO = 3:1 and MWCNT:RGO:ZnO = 3:1:0.27. wt. $\%$ = weight percent.

\subsection{Characterization}

The structure and morphology of the MWCNT-ZnO-RGO and MWCNT-RGO hybrid particles were examined by field emission scanning electron microscopy (FE-SEM, S4800, Hitachi, Tokyo, Japan, at $10 \mathrm{kV}$ ) and X-ray diffraction (XRD) (Shimadzu XRD-7000, Kyoto, Japan, Cu K $\alpha$ radiation, $\lambda=0.154 \mathrm{~nm}, 36 \mathrm{kV}$ and $\left.20 \mathrm{~mA}, 2 \theta=6-70^{\circ}, 4^{\circ} / \mathrm{min}^{-1}\right)$. The Raman spectroscopy was recorded on a Renishaw InVia Reflex Raman Microscope (Wotton-under-Edge, UK) at excitation wavelengths of $633 \mathrm{~nm}$. The electrochemical properties of electrochemical impedance spectroscopy (EIS) and cyclic voltammetry $(\mathrm{CV})$ of the specimens were operated in a three-electrode cell by a CHI760e electrochemical workstation (CH Instruments, Austin, TX, USA).

The thermal analysis of the composites was tested by a differential scanning calorimetry device (NETZSCH DSC 200 F3 Maia, Selb, Germany) under nitrogen atmosphere with the process as follows: firstly, heated from $30{ }^{\circ} \mathrm{C}$ to $150{ }^{\circ} \mathrm{C}$ with a heating rate of $10{ }^{\circ} \mathrm{C}$ per minute, then maintained at $150{ }^{\circ} \mathrm{C}$ for $5 \mathrm{~min}$ to erase the thermal history; then, cooled down to $30^{\circ} \mathrm{C}$ at the same rate of $10{ }^{\circ} \mathrm{C}$ per minute; lastly, heated to $150{ }^{\circ} \mathrm{C}$ at the same heating rate. The surface static contact angles of all specimens were examined by a contact angle device (JC2000C1, Shanghai Zhongchen Digital Technology Co., Ltd., Shanghai, China) at $23 \pm 2{ }^{\circ} \mathrm{C}$ using deionized water and $\mathrm{CH}_{2} \mathrm{I}_{2}$. The electrical conductivity of the specimens (which used at least five specimens) was tested by a digital high resistance machine (PC68, Shanghai Precision Instrument Manufacture, Shanghai, China) at $23 \pm 2{ }^{\circ} \mathrm{C}$. For the mechanical properties of the composite films, the average value was obtained from at least five specimens at $23 \pm 2{ }^{\circ} \mathrm{C}$ ), and were measured by the tensile testing machine (INSTRON 5566, DatapointLabs, Ithaca, NY, USA) at a cross-head speed of $10 \mathrm{~mm} / \mathrm{min}$. 


\section{Results and Discussion}

\subsection{Characterization of the Nanoparticles}

Figure 2 shows the XRD of the ZnO, MWCNTs, GO, MWCNTs-RGO and MWCNT-ZnO-RGO powders, respectively. The diffraction peaks of MWCNT-ZnO-RGO hybrid nanoparticles can be well indexed to the characteristic diffraction peaks of hexagonal $\mathrm{ZnO}$ (Joint Committee on Powder Diffraction Standards, JCPDS\#36-1451), which confirmed that the hexagonal structure of ZnO has successfully joined onto the hybrid during the hydrothermal process. According to the Scherrer formula, $\mathrm{D}=\mathrm{K} \lambda / \mathrm{B} \cos \theta$, where $\mathrm{K}$ is $0.89, \theta$ is the diffraction angle, and $\lambda$ is the $\mathrm{X}$-ray wavelength $(0.154 \mathrm{~nm})$. Taking the strongest diffraction peak $2 \theta=36.32$ to calculate $\mathrm{D}$, the crystallite size is $23.78 \mathrm{~nm}$. Also, a diffraction peak at $26.2^{\circ}$ appears in MWCNT-RGO and MWCNT-ZnO-RGO, which is most likely from the CNTs [37]. The characteristic diffraction peak of GO shows a sharp peak at $2 \theta=10.8^{\circ}$, corresponding to a layer distance (d-spacing) of about $0.82 \mathrm{~nm}$. However, in comparison with GO, after hydrazine reduction of GO, no characteristic peak of GO is observed in MWCNT-RGO and MWCNT-ZnO-RGO hybrid particles, proving that GO is fully exfoliated and there are no restacked as-reduced graphene sheets existing in the two hybrid nanoparticles. [38].

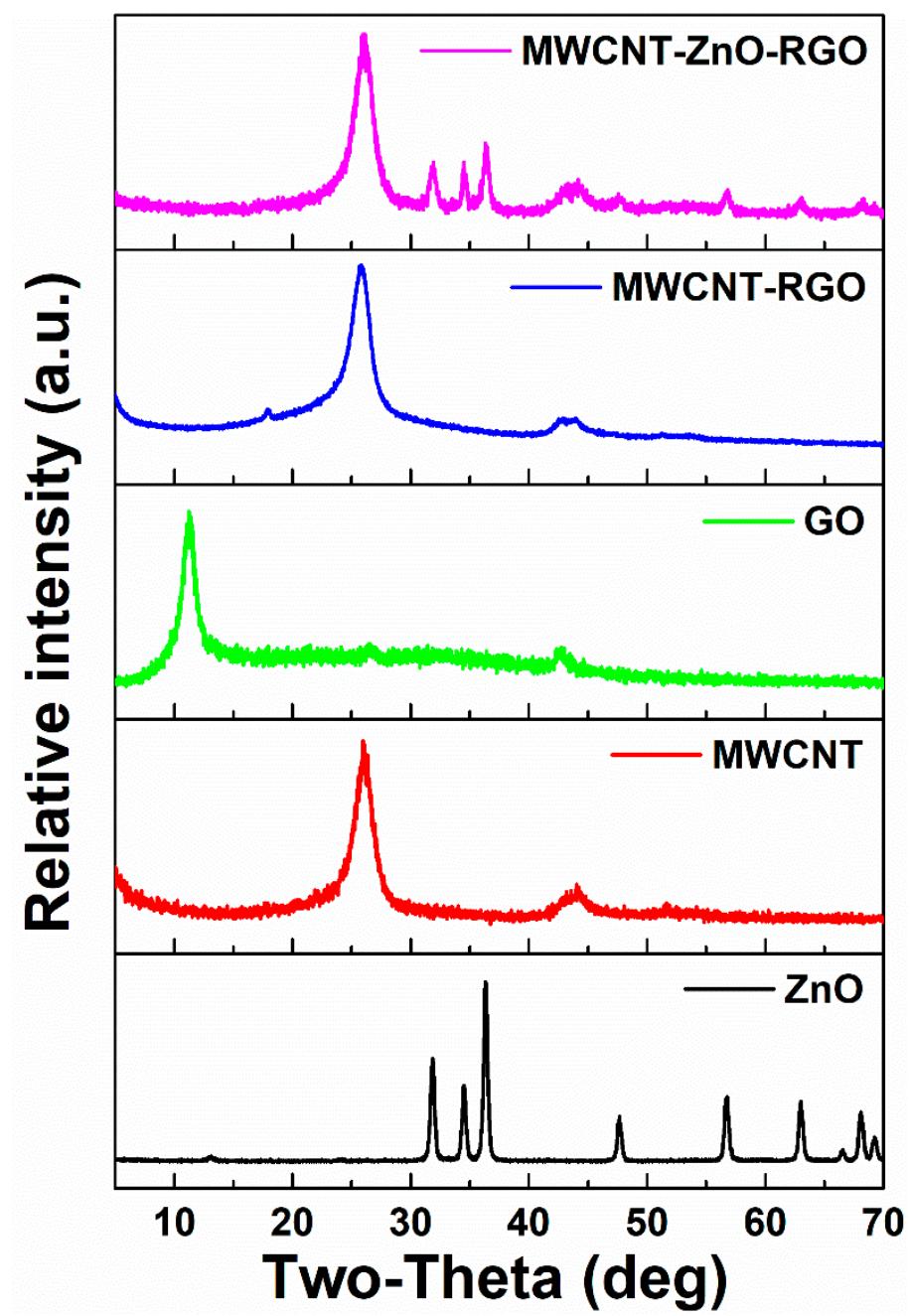

Figure 2. X-ray diffraction (XRD) patterns of ZnO, MWCNTs, GO, MWCNT-RGO, and MWCNT-ZnO-RGO powders. a.u. = arbitrary units.

The surface morphologies and microstructures of MWCNT-RGO hybrid particles and MWCNT-ZnO-RGO hybrid particles are investigated and observed by SEM. Figure 3a,b reveals 
that the MWCNTs are intertwined and covered with RGO sheets to assemble a 3D net structure. Furthermore, the RGO sheets labeled by the red dashed block in Figure $3 b$ are embraced by the MWCNTs in the MWCNT-RGO hybrid particles, and the size of the RGO is about a few microns. In Figure 3c,d, we can observe that the single $\mathrm{ZnO}$ nanorods are uniformly distributed in the 3D net structure of the MWCNT-ZnO-RGO hybrid particles with an average length and width of $300 \pm 10 \mathrm{~nm}$ and $100 \pm 5 \mathrm{~nm}$, respectively. This is larger compared with the particle size calculated from XRD, probably due to the carbon nanotubes wrapped around the surface of the $\mathrm{ZnO}$ nanorods. Also, after magnification, as shown in the yellow dashed circle (Figure 3d), the intimate contact among $\mathrm{ZnO}$, RGO and MWCNTs indicates that the three components have strong interface interactions with each other. Therefore, compared with MWCNT-RGO, in MWCNT-ZnO-RGO hybrid particles, single ZnO nanorods can not only limit the neighboring MWCNTs agglomerating, but also the RGO sheets appear more wrinkled, which is more effective to enhance the interfacial interaction between the PVC matrix and the MWCNT-ZnO-RGO filler nanoparticles, thereby improving the mechanical properties of the polymer composites.
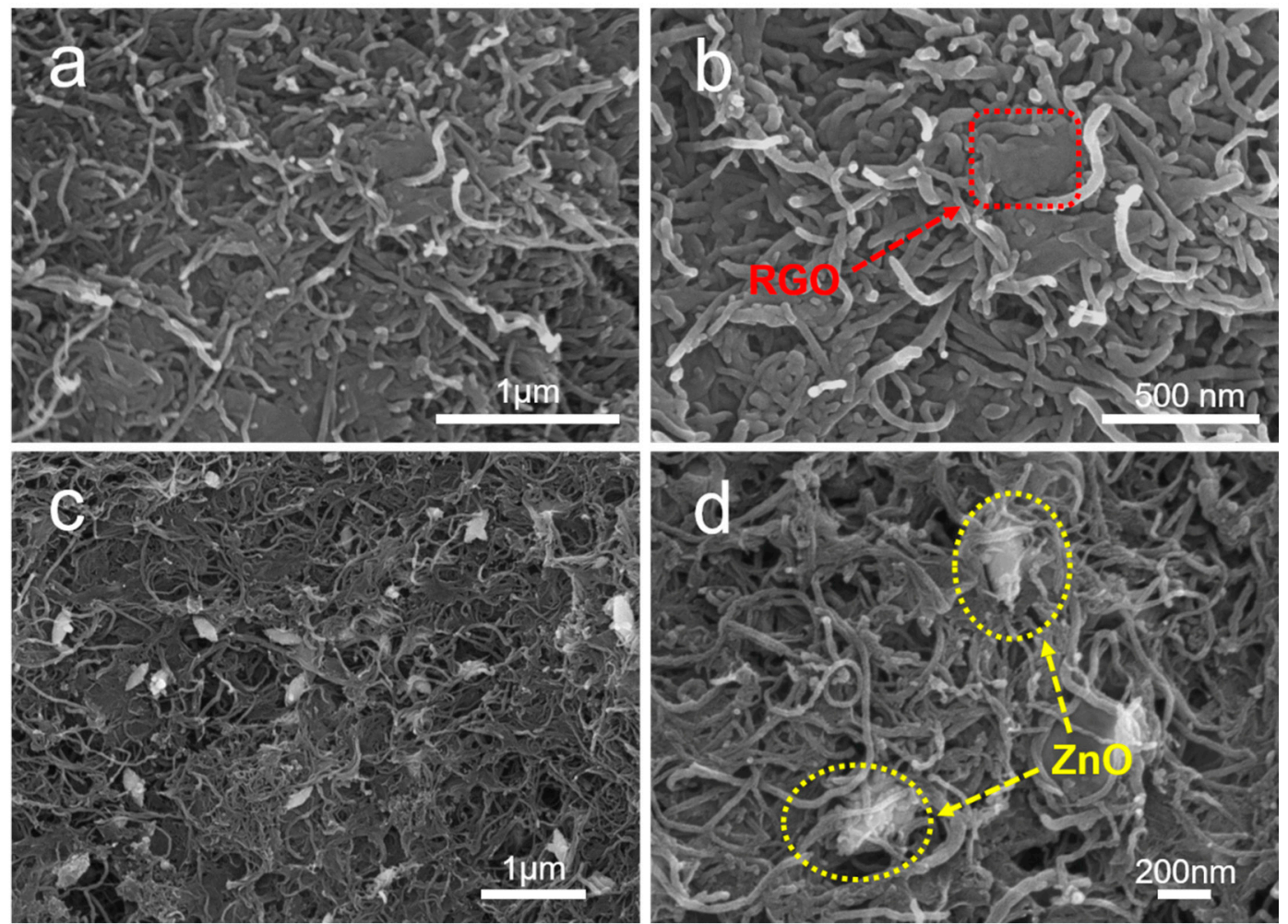

Figure 3. Scanning electron microscopy (SEM) images of the MWCNT-RGO hybrid particles (a,b) and MWCNT-ZnO-RGO hybrid particles (c,d). The RGO sheets are wrapped by the MWCNTs, and the $\mathrm{ZnO}$ nanorods are uniformly dispersed in MWCNTs.

The interactions between $\mathrm{ZnO}$ nanorods, MWCNTs and RGO are further investigated by cyclic voltammetry (CV) examination. The electrochemical properties of the MWCNT-ZnO-RGO and MWCNT-RGO hybrid particles are first carried out in a three-electrode configuration in $2 \mathrm{M} \mathrm{KOH}$ aqueous solution (Figure 4a). In the literature, it is reported that the homogeneous distribution of single metal oxides among the RGO layers or MWCNTs will improve the specific capacitance of the whole electrode [39]. Figure 4a compares the CV curves of MWCNT-ZnO-RGO and MWCNT-RGO hybrid particles. At a high scan rate of $100 \mathrm{mV} / \mathrm{s}$, we can see all the specimens exhibit symmetric charge and a nearly rectangular shape. Even at the scan rate of $10 \mathrm{~V} / \mathrm{s}$, they still keep their shapes very well (Figure 4c,d). This manifests as an excellent electrical double layer (EDL) in the electrode. Moreover, the different specific capacitances with different voltage sweep rates $(5 \mathrm{mV} / \mathrm{s}, 10 \mathrm{mV} / \mathrm{s}, 20 \mathrm{mV} / \mathrm{s}$, 
$30 \mathrm{mV} / \mathrm{s}, 50 \mathrm{mV} / \mathrm{s}, 80 \mathrm{mV} / \mathrm{s}$, and $100 \mathrm{mV} / \mathrm{s}$ ) are examined for MWCNT-ZnO-RGO and MWCNT-RGO hybrid particles. Obviously, the mass specific capacitance (CSP, $m$ ) of MWCNT-ZnO-RGO is better than the MWCNT-RGO nanofiller mass specific capacitance at all scan rates. The mass specific capacitance of all active materials, calculated from the CV curves in a three-electrode cell, is obtained from the following formula:

$$
C s p, m=\frac{Q}{2 U m}=\frac{1}{2 U v m} \int_{U-}^{U+} i(U) d U
$$

where $m$ represents the mass of the active substances used in electrochemical testing; $U(U=U+-U-)$, $Q, i(U)$ and $C s$, electrode $=\frac{2 I t}{U}$ represent the scanned potential window, total voltametric charge, current and the scan rate of the $C V$ curve, respectively. In our research, the scanned potential window is $1 \mathrm{~V}$, and $Q$ is calculated by integrating positive and negative sweeps of current in the three-electrode cell of the CV curve. Moreover, the mass specific capacitance of MWCNT-ZnO-RGO hybrid particles, obtained from the CV curve in Figure 4a, is almost 2.6 times higher than MWCNT-RGO hybrid particles. The phenomenon may ascribe to such a fact that the introduction of $\mathrm{ZnO}$ greatly increases the pore structure, resulting in a high specific surface area of the MWCNT-ZnO-RGO hybrid particles.

(a)

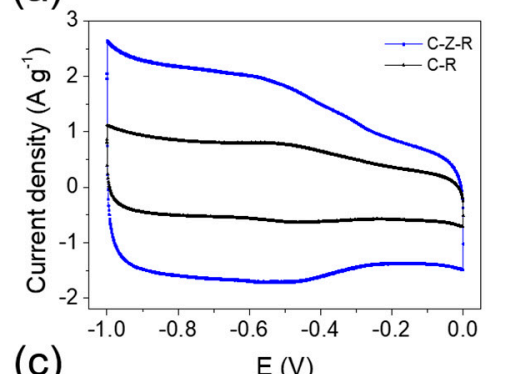

(c)

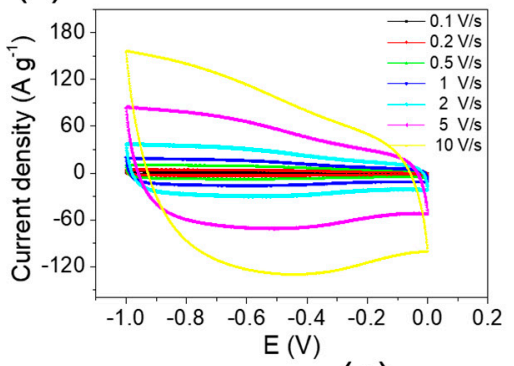

(e) (b)
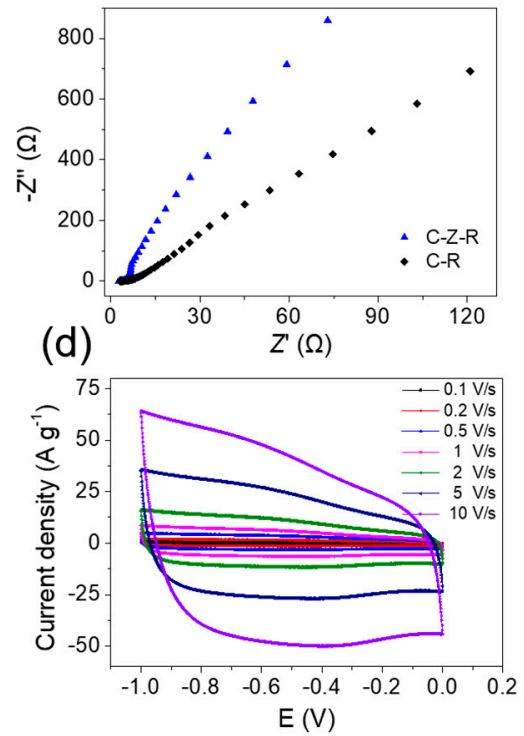

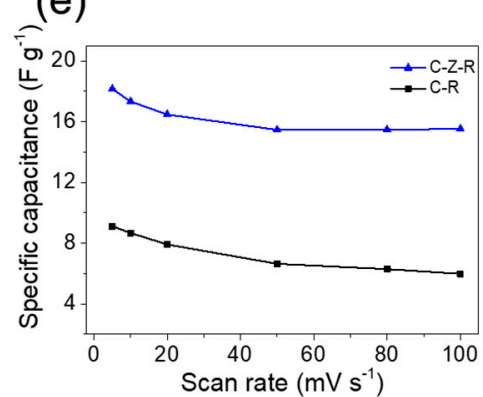

Figure 4. (a) Cyclic voltammetry (CV) curves of MWCNT-ZnO-RGO and MWCNT-RGO electrodes at the scan rate of $100 \mathrm{mV} / \mathrm{s}$ in 2M KOH. (b) Nyquist plots of MWCNT-ZnO-RGO and MWCNT-RGO. (c) CV curves of the MWCNT-ZnO-RGO electrode at different scan rates. (d) CV curves of the MWCNT-RGO electrode at different scan rates. (e) Mass specific capacitance of the MWCNT-ZnO-RGO and MWCNT-RGO electrode at different scan rates.

In order to verify the existence of $\mathrm{ZnO}$ in favor of increasing the electron and ion transport of MWCNT-ZnO-RGO compared to MWCNT-RGO hybrid particles, we carried out electrochemical impedance spectroscopy (EIS) (Figure 4e) which measured electrolytes with the frequency ranging 
from 0.01 to $1 \times 10^{6} \mathrm{~Hz}$ at $5 \mathrm{mV}$ open circuit potential in the three-electrode cell in $2 \mathrm{M} \mathrm{KOH}$ aqueous solution. From the figure, it is easy to see that the two electrode materials have no semicircle in the high-frequency region. However, in the low-frequency region, MWCNT-ZnO-RGO hybrid particles exhibit a straight line almost vertical to the real axis, suggesting an ideal capacitive behavior of the MWCNT-ZnO-RGO electrode [40]. From the above results, there is a positive synergistic effect among $\mathrm{ZnO}, \mathrm{RGO}$ and MWCNTs, indicating that there is a strong interaction between the three components. Previous studies have shown that filler particles, containing one component which has strong interfacial interaction with polymer molecular chains, leads to an enhancement of the mechanical properties [32-34,39].

\subsection{Interfacial Interaction in the PVC/MWCNT-ZnO-RGO Nanocomposites}

The dispersion and distribution of fillers in the polymer matrix, as well as their interfacial bonding, are the two key factors in influencing the high macroscopic properties of the nanocomposites. The fracture morphology of PVC/2.0 wt.\% CNT-ZnO-RGO composites and PVC/2.0 wt.\% CNT-RGO composites are presented in Figure 5, which shows the dispersion state of CNT-RGO and CNT-ZnO-RGO in the PVC matrix. The CNT-RGO particles aggregate in the PVC matrix, as shown in Figure 5a-c. The CNT-ZnO-RGO hybrid particles are almost individual and uniformly distributed in the PVC composite films (Figure $5 \mathrm{~d}-\mathrm{f}$ ), which makes a clear demonstration that $\mathrm{ZnO}$ may reduce the agglomeration of hybrid particles. It can also estimate the interfacial interactions from the SEM pictures between the hybrid particles and the PVC matrix. We can observe the gaps between the CNT-RGO particles and the PVC matrix, which means that the CNT-RGO particles have poor interaction with PVC therein. However, strong interactions detected between CNT-ZnO-RGO particles and PVC is ascribed to the $\mathrm{ZnO}$ having electrostatic/hydrogen bonding interactions with PVC chains. We can deduce that the PVC/RGO-ZnO-MWCNT composites exhibit excellent mechanical and conductive properties.

We can further prove the strong interfacial interactions between the MWCNT-ZnO-RGO filler and the PVC matrix by thermodynamic study, which calculates the spreading coefficient $\left(S_{a-b}, \mathrm{mN} / \mathrm{m}\right)$, which represents component a over component $b$ from Equation (2) [41].

$$
S_{a-b}=\gamma_{b}-\gamma_{a}-\gamma_{a b}
$$

where $\gamma_{a}, \gamma_{b}$ and $\gamma_{a b}$ represent the surface tensions of component $a$, surface tensions of component $b$ and the interfacial tension between $a$ and $b$, respectively. If $S_{a-b}$ is positive, it represents that component $\mathrm{b}$ can be wrapped up by component $a$. If the opposite is true, it will not. $\gamma_{a}$ and $\gamma_{b}$ can be obtained from Equation (2). $\gamma_{a}$ contains the dispersive and polar components of $a$, and $\gamma_{b}$ contains the dispersive and polar components of $b$, which can be obtained from the following Equation (3).

$$
(1+\cos \theta) \gamma_{l}=2\left(\sqrt{\gamma_{s}^{d} \gamma_{l}^{d}}+\sqrt{\gamma_{s}^{p} \gamma_{l}^{p}}\right)
$$

where $\theta, \gamma^{d}$ and $\gamma^{p}$ are the contact angle between a pure liquid (l) and a solid (s), dispersive and polar components of the surface tension of component $a$ and $b$, respectively. The interfacial tensions are obtained from the following harmonic-mean (Equation (4)) and geometric-mean (Equation (5)) equations [42,43]. Moreover, the spreading coefficients, evaluated from interfacial tensions, of MWCNT-ZnO-RGO and MWCNT-RGO samples are listed in Table 2. The spreading coefficients of PVC/MWCNT-ZnO-RGO composites, contrary to PVC/MWCNT-RGO, are all positive. This indicates that PVC could spread over the MWCNT-ZnO-RGO hybrid fillers. In addition, the results coincide with the conclusions we see in the above SEM pictures.

$$
\gamma_{12}=\gamma_{1}+\gamma_{2}-4\left(\frac{\gamma_{1}^{d} \gamma_{2}^{d}}{\gamma_{1}^{d}+\gamma_{2}^{d}}+\frac{\gamma_{1}^{p} \gamma_{2}^{p}}{\gamma_{1}^{p}+\gamma_{2}^{p}}\right),
$$




$$
\gamma_{12}=\gamma_{1}+\gamma_{2}-2\left(\sqrt{\gamma_{1}^{d} \gamma_{2}^{d}}+\sqrt{\gamma_{1}^{p} \gamma_{2}^{p}}\right)
$$
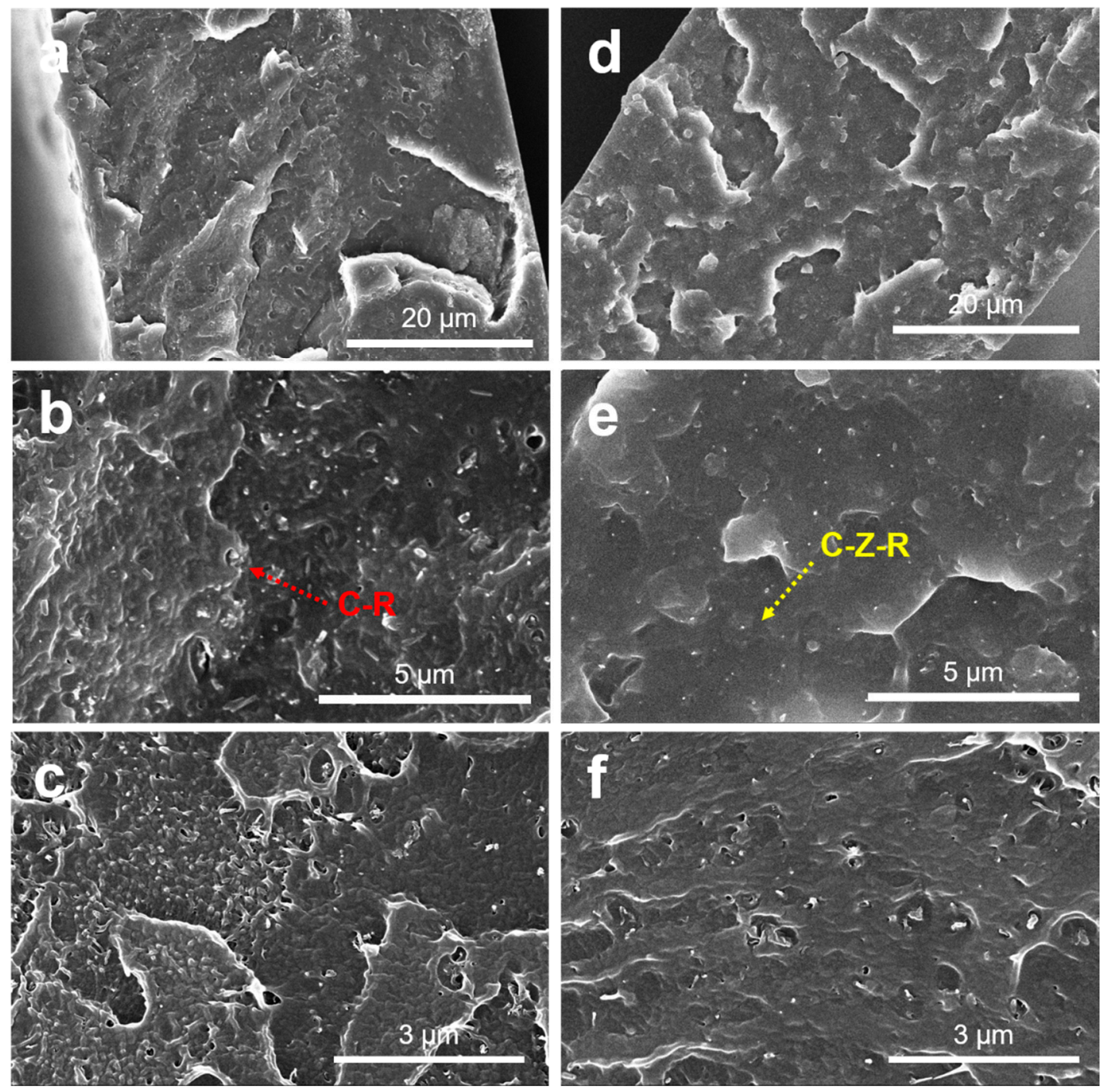

Figure 5. SEM pictures of the brittle fracture face of the PVC/2.0 wt.\% MWCNT-RGO nanocomposites $(\mathbf{a}-\mathbf{c})$ and the PVC/2.0 wt.\% MWCNT-ZnO-RGO nanocomposites (d-f).

Table 2. Surface tension, interfacial energy and spreading coefficient results of PVC, MWCNT-ZnO-RGO, and MWCNT-RGO.

\begin{tabular}{cccccccc}
\hline \multirow{2}{*}{ Samples } & \multicolumn{3}{c}{ Surface Tension $(\mathrm{mN} / \mathrm{m})$} & \multicolumn{2}{c}{$\begin{array}{c}\text { Interfacial Energies } \\
\text { with PVC }(\mathrm{mN} / \mathrm{m})\end{array}$} & \multicolumn{2}{c}{$\begin{array}{c}\text { Spreading Coefficient } \\
\text { with PVC }(\mathrm{mN} / \mathrm{m})\end{array}$} \\
\cline { 2 - 8 } & $\begin{array}{c}\text { Total } \\
(\gamma)\end{array}$ & $\begin{array}{c}\text { Dispersive } \\
\text { Part }\left(\gamma^{d}\right)\end{array}$ & $\begin{array}{c}\text { Polar Part } \\
\left(\gamma^{p}\right)\end{array}$ & Harmonic & Geometric & Harmonic & Geometric \\
\hline PVC & 43.2 & 42.0 & 1.2 & & & & \\
MWCNT-RGO & 71.2 & 69.04 & 2.16 & 6.86 & 50.76 & -34.86 & -78.75 \\
MWCNT-ZnO-RGO & 25.72 & 25.5 & 0.22 & 4.74 & 2.45 & 12.74 & 15.03 \\
\hline
\end{tabular}

Raman spectroscopy is used to demonstrate the interactions on the molecular structure of an element in the composites. Figure 6a shows the Raman spectra for the PVC, the PVC $/ 2.0 \mathrm{wt} . \%$ MWCNT-ZnO-RGO composites and the PVC/2.0 wt.\% MWCNT-RGO composites. The main characteristic peak positions of the Raman spectroscopy in PVC are as follows: the band structure of $\mathrm{C}-\mathrm{Cl}$ stretching, the $\mathrm{C}-\mathrm{C}$ stretching vibration double bonds, the $\mathrm{CH}_{2}$ twist- $\mathrm{CH}_{2}$ wag vibrational 
and $\mathrm{CH}_{2}$ bending come out at $600-700 \mathrm{~cm}^{-1}, 1127 \mathrm{~cm}^{-1}$ and $1515 \mathrm{~cm}^{-1}, 1335 \mathrm{~cm}^{-1}$ and $1432 \mathrm{~cm}^{-1}$, respectively [44].
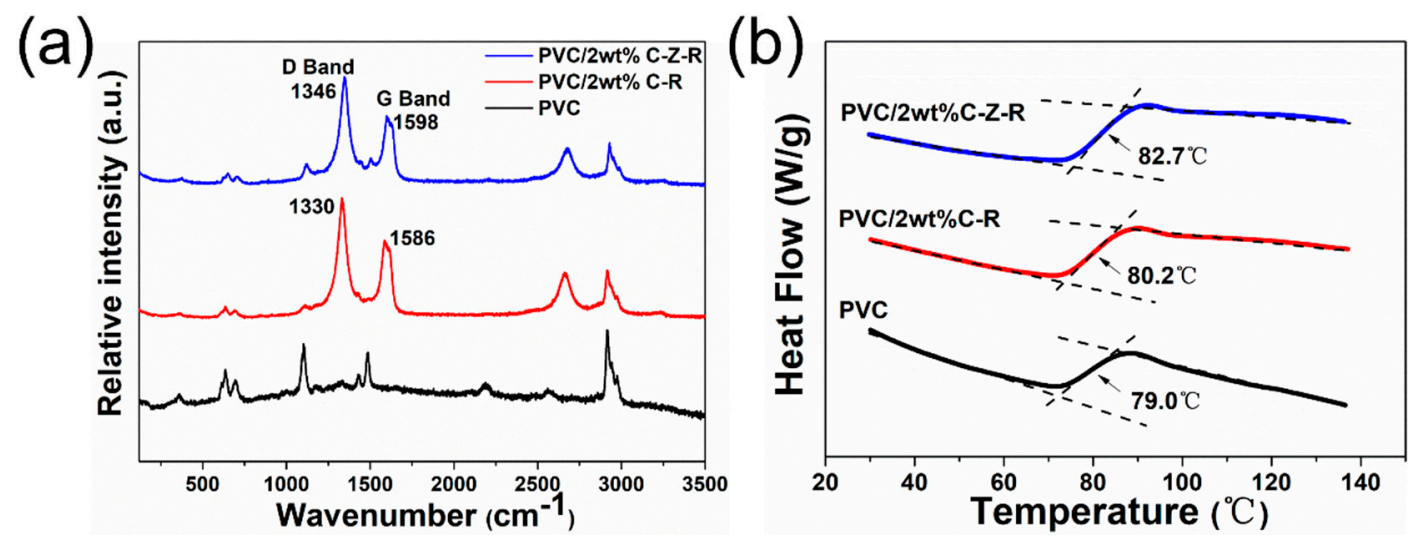

Figure 6. The Raman spectra (a) and the glass transition temperature (b) of the PVC, the PVC/2.0 wt.\% MWCNT-ZnO-RGO composites and the PVC/2.0 wt.\% MWCNT-RGO composites.

The $\mathrm{D}$ band and $\mathrm{G}$ band are shown in the Raman spectra of the PVC/2.0 wt.\% MWCNT-ZnO-RGO and the PVC/2.0 wt.\% MWCNT-RGO composites. The D band and G band are attributed to the vibration of disordered $\mathrm{sp}^{2}$-bonded carbon atoms and the vibration of $\mathrm{sp}^{2}$-bond carbon atoms in the two-dimensional hexagonal lattice, respectively. The $\mathrm{C}-\mathrm{C}$ stretching vibration double bonds appeared at around $1127 \mathrm{~cm}^{-1}$ and $1515 \mathrm{~cm}^{-1}$. With the addition of $\mathrm{ZnO}$, the maximum in the $\mathrm{D}$ band peak is moved by $16 \mathrm{~cm}^{-1}$ and the $\mathrm{G}$ band peak is moved by $12 \mathrm{~cm}^{-1}$. The shifting of the $\mathrm{D}$ and $\mathrm{G}$ band peaks can be accounted for by the existence of $\mathrm{ZnO}$ nanorods that exhibit electrostatic/hydrogen bonding with PVC chains and dispersion in the PVC matrix as a result of polymer penetration into the MWCNT-ZnO-RGO hybrid particles during mixing [45].

The interface interaction between the polymer matrix and the filler in the polymer nanocomposites can be further studied from the glass transition temperature $(\mathrm{Tg})$. Figure $6 \mathrm{~b}$ reveals that the corresponding Tg of pure PVC, PVC/2.0 wt.\% RGO-MWCNT composites and PVC/2.0 wt.\% RGO-ZnO-MWCNT composites are $79.0^{\circ} \mathrm{C}, 80.2^{\circ} \mathrm{C}$ and $82.7^{\circ} \mathrm{C}$, respectively. The $\mathrm{Tg}$ of these two composites are both higher than the pure PVC polymer, which is perhaps ascribed to the enhancement of the interfacial interaction between the PVC molecular chains and the two different nanofillers. Furthermore, the glass transition temperature of PVC/2.0 wt.\% RGO-ZnO-MWCNT composites is $2.5^{\circ} \mathrm{C}$ higher than PVC $/ 2.0 \mathrm{wt} . \%$ RGO-MWCNT composites at the same content of particles. This indicates that the presence of $\mathrm{ZnO}$ nanorods could further restrict the chain segment mobility of PVC.

The electrical conductivity of the composites is plotted as a function of RGO-MWCNT and RGO-ZnO-MWCNT content in Figure 7. This figure shows typical percolation behavior: the approximate percolation thresholds are found to be around $1.0 \mathrm{wt} . \%$ filler content. It is usually considered that a conductive network exists in PVC/RGO-MWCNT and PVC/RGO-ZnO-MWCNT composites in which the fillers form a conductive path when the filler loading reaches the conductivity threshold. The incorporation of $5.0 \mathrm{wt} . \%$ RGO-MWCNT and RGO-ZnO-MWCNT increased the electric conductivity of the composites to $8.72 \times 10^{-5} \mathrm{~S} / \mathrm{m}$ and $3.32 \times 10^{-4} \mathrm{~S} / \mathrm{m}$-about eleven orders of magnitude compared to the pure PVC $\left(2.89 \times 10^{-15} \mathrm{~S} / \mathrm{m}\right)$. However, the composites containing RGO-ZnO-MWCNT exhibit a more conspicuous enhancement in electrical conductivity than their counterparts containing RGO-MWCNT, especially if the filler content is below $1.0 \mathrm{wt} . \%$. At the same content (0.1 wt.\% and $0.5 \mathrm{wt} . \%)$, the electric conductivity of the PVC/RGO-ZnO-MWCNT composites increased to $2.31 \times 10^{-11} \mathrm{~S} / \mathrm{m}$ and $3.68 \times 10^{-10} \mathrm{~S} / \mathrm{m}$, while the electric conductivity of the PVC/RGO-MWCNT composites increased to $1.57 \times 10^{-13} \mathrm{~S} / \mathrm{m}$ and $1.78 \times 10^{-12} \mathrm{~S} / \mathrm{m}$, showing the advantage of $\mathrm{ZnO}$ nanorods acting as efficient joint points to enhance the conductivity of the nanocomposites. 


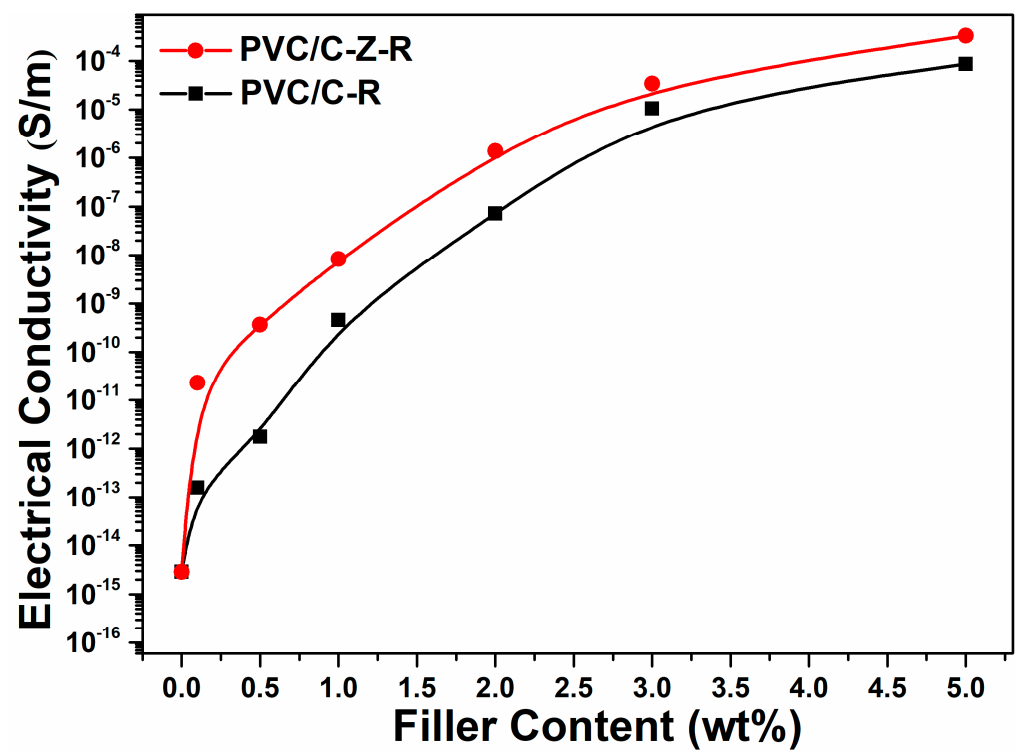

Figure 7. The electrical conductivity of composites varied by filler content. The content of MWCNT-RGO and MWCNT-ZnO-RGO particles are varied from 0 wt. $\%, 0.1 \mathrm{wt} . \%, 0.5 \mathrm{wt} . \%, 1.0 \mathrm{wt} . \%$, 2.0 wt. $\%, 3.0$ wt. $\%$ and 5.0 wt. $\%$ in PVC.

The dispersion of fillers in the matrix and their interactions affect the nano- and micro-structures in the polymer composite, thereby affecting the composite's mechanical properties. The tensile strength (Figure 8a) and Young's modulus (Figure 8b) of the PVC composites with different RGO-MWCNT and RGO-ZnO-MWCNT filler contents ranging from $0.1 \mathrm{wt} . \%$ to $5.0 \mathrm{wt} . \%$ are shown. Obviously, incorporation of low content RGO-ZnO-MWCNT hybrid particles, i.e., not more than $2.0 \mathrm{wt} . \%$, enhances both the tensile strength and Young's modulus in the PVC composites. As the RGO-ZnO-MWCNT hybrid particle loading reaches $2.0 \mathrm{wt} . \%$, the tensile strength reaches the maximum value of $68.6 \mathrm{MPa}$, which is enhanced by $30.8 \%$ compared to the unfilled PVC (52.6 MPa). On the contrary, the tensile strength is reduced by $41.3 \%$ (30.9 MPa) after the addition of $1.0 \mathrm{wt} . \%$ RGO-MWCNT fillers to the PVC matrix. Moreover, the incorporation of RGO-ZnO-MWCNT hybrid particles exhibits a great effect on the Young's modulus of PVC. In the range of $0.1-1.0 \mathrm{wt} . \%$ of RGO-ZnO-MWCNT fillers, composites show a continuous increase in Young's modulus with the increase in filler amount. The highest value is achieved with $1.0 \mathrm{wt}$.\% RGO-ZnO-MWCNT fillers (3.7 GPa), which is increased by $60.9 \%$ compared to the value of the unfilled PVC ( $2.3 \mathrm{GPa})$. However, the Young's modulus of the PVC/RGO-MWCNT composites is decreased with an increased loading of RGO-MWCNT particles up to $5.0 \mathrm{wt} . \%$, and the minimum value at $1.0 \mathrm{wt} . \%$ is increased by $30.4 \%$ compared to pure PVC.
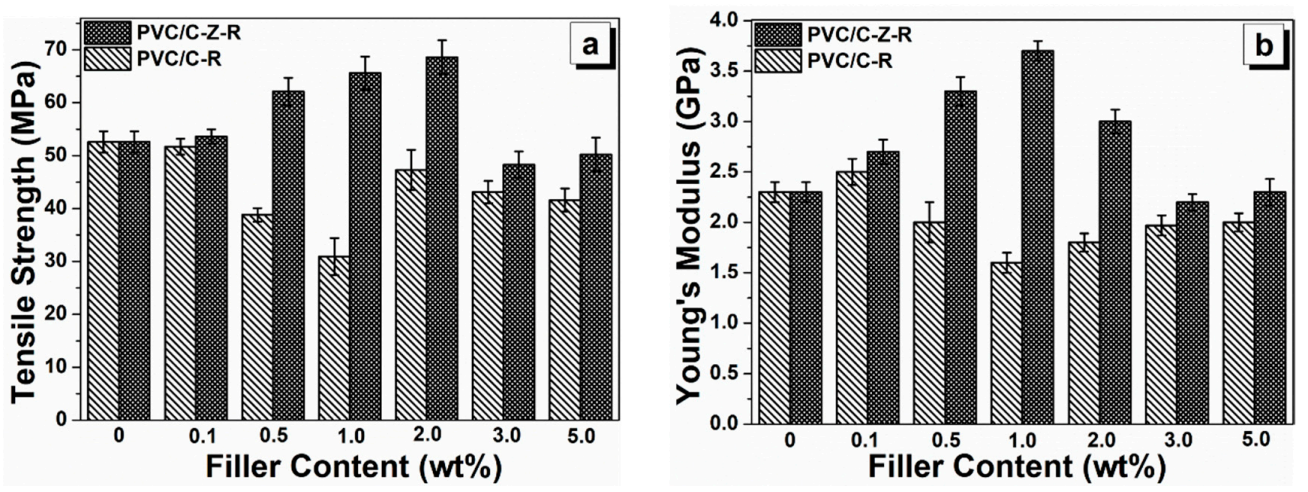

Figure 8. The tensile strength (a) and Young's modulus (b) of the PVC composite films with different particles. The content of MWCNT-RGO and MWCNT-ZnO-RGO particles are varied from $0 \mathrm{wt} . \%$, 0.1 wt.\%, 0.5 wt. \%, 1.0 wt. \%, 2.0 wt.\%, 3.0 wt.\% and 5.0 wt.\% in PVC. 
To reveal the reasons for the reinforcing mechanism, the fractured surface of PVC/2.0 wt.\% RGO-MWCNT and PVC/2.0 wt.\% RGO-ZnO-MWCNT composites after tensile testing are investigated by SEM. As shown in Figure 9a,b, the fractured faces of the PVC/RGO-MWCNT composites are rough and have many cavities. These results indicate that the PVC/RGO-MWCNT composites are prone to semi-brittle failure and have a weak interfacial interaction between RGO-MWCNT nanoparticles and PVC molecular chains. Nevertheless, compared with the PVC/RGO-MWCNT composites, Figure 9b,c revealed that the fractured faces of PVC/RGO-ZnO-MWCNT composites are more smooth and flat. At the beginning of the stretching process in the neck of the samples, the stress causes the debonded particles to locally increase at the particle-polymer interface. For further stretching, these debonded areas would form many holes on account of bad interactions with the polymer matrix [46]. It can be seen that many voids developed in the course of the stretching in Figure $9 \mathrm{a}, \mathrm{b}$. In contrast, the tensile fractured surface of PVC/RGO-ZnO-MWCNT composites showed fewer defects. These consequences demonstrate that the RGO-ZnO-MWCNT hybrid particles have tough interfacial interactions with the PVC molecular chains, whereas there were poor interfacial interactions between the RGO-MWCNT nanoparticles and the PVC molecular chains.
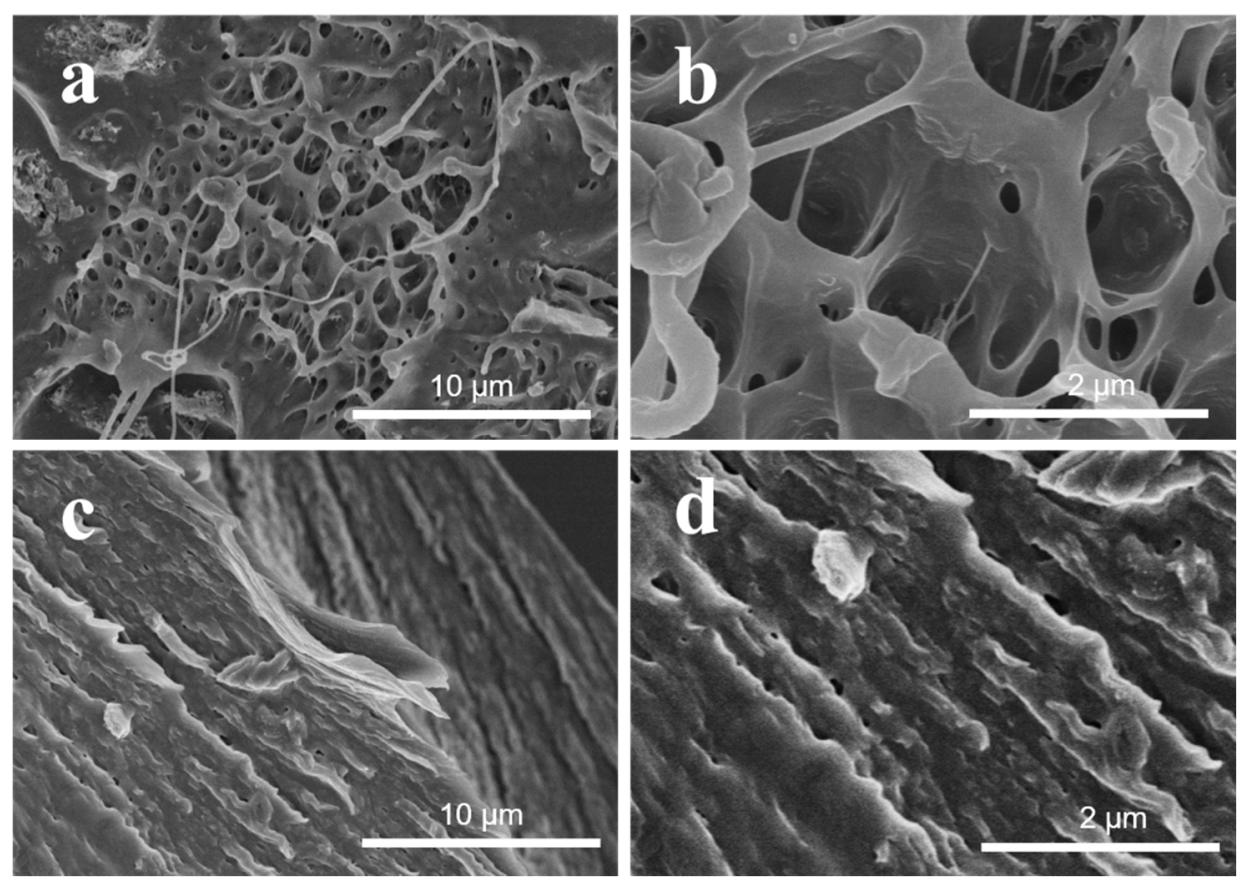

Figure 9. SEM pictures of the tensile fractured surface of the PVC/2.0 wt.\% MWCNT-RGO particles $(\mathbf{a}, \mathbf{b})$ and the PVC/2.0 wt.\% MWCNT-ZnO-RGO nanocomposites (c,d).

The improvement of the mechanical properties is accounted for by the better interfacial adhesion of PVC and RGO-ZnO-MWCNT hybrid fillers. The presence of ZnO nanorods acts to afford stable interphase interactions that are dominated by electrostatic interactions and $\mathrm{p}-\pi$ stacking interactions between RGO and MWCNTs and hydrogen bonding and electrostatic interactions with the PVC molecular chains. These $\mathrm{Zn}^{2+}$ ions absorb onto the external surface of RGO through electrostatic interactions and $\mathrm{p}-\pi$ stacking interactions to generate stable RGO-ZnO-MWCNT particles. The strong dipole attraction of $\mathrm{ZnO}$ is beneficial for hydrogen bonding and electrostatic interaction with PVC molecular chains. Therefore, ZnO nanorods could act as a "joint" to connect the RGO-ZnO-MWCNT and PVC molecular chains. With regard to the PVC/RGO-MWCNT composites, the RGO-MWCNT particles have no interaction with PVC molecular chains, resulting in weak interactions with PVC and agglomerations in the PVC matrix. 


\section{Conclusions}

In summary, a facile in-situ method is established for $\mathrm{ZnO}$ nanorod decoration onto RGO-MWCNT hybrids by utilizing ZnO as a bridge to connect RGO-MWCNT fillers and PVC chains. We have prepared PVC composites containing RGO-ZnO-MWCNT hybrid particles. The ZnO nanorods interact strongly with MWCNTs and RGO through $\mathrm{p}-\pi$ stacking/electrostatic interactions without destroying their own structure. Moreover, the $\mathrm{ZnO}$ nanorods uniformly distribute in a three-dimensional (3D) network which consists of the one-dimensional structure of MWCNTs and two-dimensional structure of RGO, similar to the "joints" in fishing nets. The tensile strength and Young's modulus of PVC increase by $30.8 \%$ (68.6 MPa) and $60.9 \%$ (3.7 GPa) when adding 2.0 wt.\% and $1.0 \mathrm{wt} . \%$ RGO-ZnO-MWCNT hybrid particles, respectively. The electrical conductivity of composites with RGO-ZnO-MWCNT hybrid particles is significantly higher than those containing RGO-MWCNT hybrid particles, especially if the filler content is below $1.0 \mathrm{wt} . \%$. The improvement in electrical conductivity and mechanical properties is basically ascribed to the presence of $\mathrm{ZnO}$. The $\mathrm{Zn}^{2+}$ ions have electrostatic interactions and $\mathrm{p}-\pi$ stacking interactions with RGO and MWCNTs to generate the steady RGO-ZnO-MWCNT hybrid particles. The hydrogen bonds and electrostatic attraction interactions exist between the $\mathrm{ZnO}$ nanorods and the PVC molecular chains.

Author Contributions: G.H. and F.Q. conceived the idea of this study, designed the experiments and analyzed the results; F.Q., M.H. and G.Z. performed the experiments, analyzed the data and discussed the experimental results; F.Q. and G.H. wrote the paper. All authors of the article provided substantive comments.

Funding: This work was supported by the Fundamental Research for the Central Universities (2017MS028), and the Guangdong Science and Technology Project (2016B020242002), the National Key Research and Development Program of China (Grant No. 2016YFB0302300), the Key Program of National Natural Science Foundation of China (Grant No. 51435005), the National Natural Science Foundation of China (Grant No. 51505153), the PhD Start-up Fund of Natural Science Foundation of Guangdong Province, China (Grant No. 2016A030310429), the Science and Technology Program of Guangzhou, China (Grant No. 201607010240), the Natural Science Foundation of Guangdong Province (Grant No. 2016A030313486 and 2018A030313275), the Program of Nanhai Talented Team (Grant No. 201609180006) and the Program of Foshan Innovative Entrepreneurial Team (Grant No. 2016IT100152).

Conflicts of Interest: The authors declare no conflict of interest.

\section{References}

1. Madaleno, L.; Schjødt-Thomsen, J.; Pinto, J.C. Morphology, thermal and mechanical properties of PVC/MMT nanocomposites prepared by solution blending and solution blending+ melt compounding. Compos. Sci. Technol. 2010, 70, 804-814. [CrossRef]

2. Ebnalwaled, A.; Thabet, A. Controlling the optical constants of PVC nanocomposite films for optoelectronic applications. Synth. Met. 2016, 220, 374-383. [CrossRef]

3. Mallakpour, S.; Madani, M. Effect of functionalized $\mathrm{TiO}_{2}$ on mechanical, thermal and swelling properties of chitosan-based nanocomposite films. Polym. Plast. Technol. Eng. 2015, 54, 1035-1042. [CrossRef]

4. Owen, J. Degradation and Stabilisation of PVC; Springer Science \& Business Media: Berlin, Germany, 2012.

5. Rabek, J.F. Polymer Photodegradation: Mechanisms and Experimental Methods; Springer Science \& Business Media: Berlin, Germany, 2012.

6. William Coaker, A. Fire and flame retardants for PVC. J. Vinyl Addit. Technol. 2003, 9, 108-115. [CrossRef]

7. Ghaemy, M.; Nasab, S.A. Synthesis and identification of organosoluble polyamides bearing a triaryl imidazole pendent: Thermal, photophysical, chemiluminescent, and electrochemical characterization with a modified carbon nanotube electrode. React. Funct. Polym. 2010, 70, 306-313. [CrossRef]

8. Wu, G.-H.; Liu, S.-Q.; Wu, X.-Y.; Ding, X.-M. Influence of MWCNTs modified by silane coupling agent KH570 on the properties and structure of MWCNTs/PLA composite film. J. Polym. Res. 2016, 23, 155. [CrossRef]

9. Li, J.; Wu, Z.; Huang, C.; Liu, H.; Huang, R.; Li, L. Mechanical properties of cyanate ester/epoxy nanocomposites modified with plasma functionalized MWCNTs. Compos. Sci. Technol. 2014, 90, 166-173. [CrossRef]

10. Karousis, N.; Tagmatarchis, N.; Tasis, D. Current progress on the chemical modification of carbon nanotubes. Chem. Rev. 2010, 110, 5366-5397. [CrossRef] [PubMed] 
11. Altintas, O.; Riazi, K.; Lee, R.; Lin, C.Y.; Coote, M.L.; Wilhelm, M.; Barner-Kowollik, C. RAFT-based polystyrene and polyacrylate melts under thermal and mechanical stress. Macromolecules 2013, 46, 8079-8091. [CrossRef]

12. Mallakpour, S.; Abdolmaleki, A.; Azimi, F. Ultrasonic-assisted biosurface modification of multi-walled carbon nanotubes with Thiamine and its influence on the properties of PVC/Tm-MWCNTs nanocomposite films. Ultrason. Sonochem. 2017, 39, 589-596. [CrossRef] [PubMed]

13. Mkhabela, V.J.; Mishra, A.K.; Mbianda, X.Y. Thermal and mechanical properties of phosphorylated multiwalled carbon nanotube/polyvinyl chloride composites. Carbon 2011, 49, 610-617. [CrossRef]

14. Broza, G.; Piszczek, K.; Schulte, K.; Sterzynski, T. Nanocomposites of poly(vinyl chloride) with carbon nanotubes (CNT). Compos. Sci. Technol. 2007, 67, 890-894. [CrossRef]

15. Mamunya, Y.; Boudenne, A.; Lebovka, N.; Ibos, L.; Candau, Y.; Lisunova, M. Electrical and thermophysical behaviour of PVC-MWCNT nanocomposites. Compos. Sci. Technol. 2008, 68, 1981-1988. [CrossRef]

16. Wimalasiri, Y.; Zou, L. Carbon nanotube/graphene composite for enhanced capacitive deionization performance. Carbon 2013, 59, 464-471. [CrossRef]

17. Hu, H.; Zhao, L.; Liu, J.; Liu, Y.; Cheng, J.; Luo, J.; Liang, Y.; Tao, Y.; Wang, X.; Zhao, J. Enhanced dispersion of carbon nanotube in silicone rubber assisted by graphene. Polymer 2012, 53, 3378-3385. [CrossRef]

18. Song, P.A.; Liu, L.; Fu, S.; Yu, Y.; Jin, C.; Wu, Q.; Zhang, Y.; Li, Q. Striking multiple synergies created by combining reduced graphene oxides and carbon nanotubes for polymer nanocomposites. Nanotechnology 2013, 24, 125704. [CrossRef] [PubMed]

19. Bilalis, P.; Katsigiannopoulos, D.; Avgeropoulos, A.; Sakellariou, G. Non-covalent functionalization of carbon nanotubes with polymers. RSC Adv. 2014, 4, 2911-2934. [CrossRef]

20. Gupta, J.; Wan, C.; Haddleton, D.M.; McNally, T. Plasticisation and compatibilisation of poly (propylene) with poly (lauryl acrylate) surface modified MWCNTs. Polymer 2017, 133, 89-101. [CrossRef]

21. Gupta, J.; Keddie, D.J.; Wan, C.; Haddleton, D.M.; McNally, T. Functionalisation of MWCNTs with poly (lauryl acrylate) polymerised by Cu (0)-mediated and RAFT methods. Polym. Chem. 2016, 7, 3884-3896. [CrossRef]

22. Zhou, J.; Lubineau, G. Improving electrical conductivity in polycarbonate nanocomposites using highly conductive PEDOT/PSS coated MWCNTs. ACS Appl. Mater. Interface 2013, 5, 6189-6200. [CrossRef] [PubMed]

23. Zhou, J.; Aguilar Ventura, I.; Lubineau, G. Probing the role of poly (3, 4-ethylenedioxythiophene)/poly (styrenesulfonate)-coated multiwalled carbon nanotubes in the thermal and mechanical properties of polycarbonate nanocomposites. Ind. Eng. Chem. Res. 2014, 53, 3539-3549. [CrossRef]

24. Ventura, I.A.; Zhou, J.; Lubineau, G. Drastic modification of the piezoresistive behavior of polymer nanocomposites by using conductive polymer coatings. Compos. Sci. Technol. 2015, 117, 342-350. [CrossRef]

25. Ventura, I.A.; Zhou, J.; Lubineau, G. Investigating the inter-tube conduction mechanism in polycarbonate nanocomposites prepared with conductive polymer-coated carbon nanotubes. Nanoscale Res. Lett. 2015, 10, 485. [CrossRef] [PubMed]

26. Zhu, J.; Zeng, G.; Nie, F.; Xu, X.; Chen, S.; Han, Q.; Wang, X. Decorating graphene oxide with CuO nanoparticles in a water-isopropanol system. Nanoscale 2010, 2, 988-994. [CrossRef] [PubMed]

27. Pendashteh, A.; Mousavi, M.F.; Rahmanifar, M.S. Fabrication of anchored copper oxide nanoparticles on graphene oxide nanosheets via an electrostatic coprecipitation and its application as supercapacitor. Electrochim. Acta 2013, 88, 347-357. [CrossRef]

28. Nasiri, N.; Bo, R.; Wang, F.; Fu, L.; Tricoli, A. Ultraporous Electron-Depleted ZnO Nanoparticle Networks for Highly Sensitive Portable Visible-Blind UV Photodetectors. Adv. Mater. 2015, 27, 4336-4343. [CrossRef] [PubMed]

29. Zhang, X.-L.; Zhao, X.; Liu, Z.-B.; Shi, S.; Zhou, W.-Y.; Tian, J.-G.; Xu, Y.-F.; Chen, Y.-S. Nonlinear optical and optical limiting properties of graphene oxide- $\mathrm{Fe}_{3} \mathrm{O}_{4}$ hybrid material. J. Optic. 2011, 13, 075202. [CrossRef]

30. Xie, G.; Xi, P.; Liu, H.; Chen, F.; Huang, L.; Shi, Y.; Hou, F.; Zeng, Z.; Shao, C.; Wang, J. A facile chemical method to produce superparamagnetic graphene oxide- $\mathrm{Fe}_{3} \mathrm{O}_{4}$ hybrid composite and its application in the removal of dyes from aqueous solution. J. Mater. Chem. 2012, 22, 1033-1039. [CrossRef]

31. Kim, Y.; Lee, J.-H.; Cho, S.; Kwon, Y.; In, I.; Lee, J.; You, N.-H.; Reichmanis, E.; Ko, H.; Lee, K.-T. Additive-free hollow-structured $\mathrm{Co} 3 \mathrm{O} 4$ nanoparticle Li-ion battery: The origins of irreversible capacity loss. ACS Nano 2014, 8, 6701-6712. [CrossRef] [PubMed] 
32. Olad, A.; Nosrati, R. Preparation and corrosion resistance of nanostructured PVC/ZnO-polyaniline hybrid coating. Prog. Organic Coat. 2013, 76, 113-118. [CrossRef]

33. Elashmawi, I.; Hakeem, N.; Marei, L.; Hanna, F. Structure and performance of ZnO/PVC nanocomposites. Phys. B Conden. Matter 2010, 405, 4163-4169. [CrossRef]

34. Šupová, M.; Martynková, G.S.; Barabaszová, K. Effect of nanofillers dispersion in polymer matrices: A review. Sci. Adv. Mater. 2011, 3, 1-25. [CrossRef]

35. Chen, J.; Yao, B.; Li, C.; Shi, G. An improved Hummers method for eco-friendly synthesis of graphene oxide. Carbon 2013, 64, 225-229. [CrossRef]

36. Uekawa, N.; Yamashita, R.; Wu, Y.J.; Kakegawa, K. Effect of alkali metal hydroxide on formation processes of zinc oxide crystallites from aqueous solutions containing $\mathrm{Zn}(\mathrm{OH})_{4}{ }^{2-}$ ions. Phys. Chem. Chem. Phys. 2004, 6, 442-446. [CrossRef]

37. Yan, J.; Feng, L.; Zhong, R.W. Catalytic growth of carbon nanotubes with large inner diameters. J. Serb. Chem. Soc. 2005, 70, 277-282. [CrossRef]

38. Cai, D.; Song, M. Preparation of fully exfoliated graphite oxide nanoplatelets in organic solvents. J. Mater. Chem. 2007, 17, 3678-3680. [CrossRef]

39. Li, P.; Chen, X.; Zeng, J.-B.; Gan, L.; Wang, M. Enhancement of the interfacial interaction between poly (vinyl chloride) and zinc oxide modified reduced graphene oxide. RSC Adv. 2016, 6, 5784-5791. [CrossRef]

40. Li, P.; Li, J.; Zhao, Z.; Fang, Z.; Yang, M.; Yuan, Z.; Zhang, Y.; Zhang, Q.; Hong, W.; Chen, X. A General Electrode Design Strategy for Flexible Fiber Micro-Pseudocapacitors Combining Ultrahigh Energy and Power Delivery. Adv. Sci. 2017, 4, 1700003. [CrossRef] [PubMed]

41. Harkins, W.D. The Physical Chemistry of Surface Films; Reinhold: New York, NY, USA, 1952.

42. Fenouillot, F.; Cassagnau, P.; Majesté, J.-C. Uneven distribution of nanoparticles in immiscible fluids: Morphology development in polymer blends. Polymer 2009, 50, 1333-1350. [CrossRef]

43. Zhang, S.; Deng, H.; Zhang, Q.; Fu, Q. Formation of conductive networks with both segregated and double-percolated characteristic in conductive polymer composites with balanced properties. ACS Appl. Mater. Interface 2014, 6, 6835-6844. [CrossRef] [PubMed]

44. Voyiatzis, G.; Andrikopoulos, K.; Papatheodorou, G.; Kamitsos, E.; Chryssikos, G.D.; Kapoutsis, J.; Anastasiadis, S.; Fytas, G. Polarized resonance Raman and FTIR reflectance spectroscopic investigation of the molecular orientation in industrial poly (vinyl chloride) specimens. Macromolecules 2000, 33, 5613-5623. [CrossRef]

45. McNally, T.; Pötschke, P.; Halley, P.; Murphy, M.; Martin, D.; Bell, S.E.; Brennan, G.P.; Bein, D.; Lemoine, P.; Quinn, J.P. Polyethylene multiwalled carbon nanotube composites. Polymer 2005, 46, 8222-8232. [CrossRef]

46. Xie, X.-L.; Liu, Q.-X.; Li, R.K.-Y.; Zhou, X.-P.; Zhang, Q.-X.; Yu, Z.-Z.; Mai, Y.-W. Rheological and mechanical properties of PVC/CaCO3 nanocomposites prepared by in situ polymerization. Polymer 2004, 45, 6665-6673. [CrossRef]

(C) 2018 by the authors. Licensee MDPI, Basel, Switzerland. This article is an open access article distributed under the terms and conditions of the Creative Commons Attribution (CC BY) license (http:/ / creativecommons.org/licenses/by/4.0/). 